\title{
HENRY TAUBE CENTENARY - SOME REMARKS OF A GREAT SCIENTIST IN BRAZIL
}

\author{
Henrique E. Toma* \\ Departamento de Química Fundamental, Instituto de Química, Universidade de São Paulo, Av. Prof. Lineu Prestes, 748, 05508- \\ 000 São Paulo - SP, Brasil
}

Recebido em 18/02/2015; aceito em 07/03/2015; publicado na web em 28/03/2016

On the last day of November 2015, Henry Taube (Figure 1) would celebrate his $100^{\text {th }}$ birthday anniversary. The World has missed this great scientist, who passed away on November 15, 2005. Henry Taube received the Nobel Prize in Chemistry, in 1983, and his major scientific achievements and importance to Brazil have already been highlighted in the Editorial page of Journal of the Brazilian Chemical Society. ${ }^{1}$ Now, by occasion of his centenary birth year, he truly deserves an appreciation from the Brazilian community, specially by his scientific heritage which is now consolidated in the country, and by his efforts in establishing the new paradigms implanted by the NAS/CNPq Program (1969-1977).

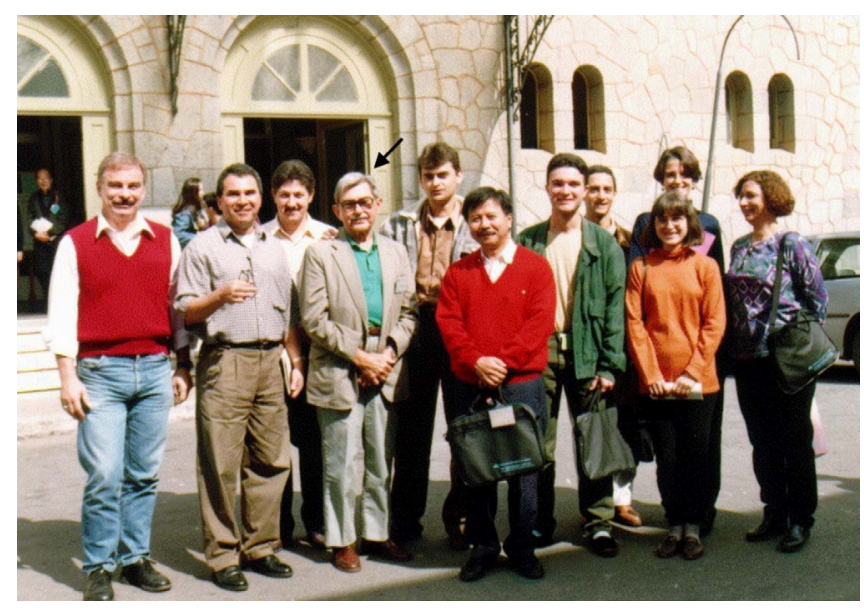

Figure 1. Henry Taube, plenary lecturer at the $19^{\text {th }}$ Annual Meeting of the Brazilian Chemical Society (1996), Poços de Caldas, Brazil

This program, involving the National Academy of Sciences (USA) and the Conselho Nacional de Desenvolvimento Científico e Tecnológico (CNPq), was played by top scientists such as Henry Taube (Stanford University), Harry B. Gray (Caltech), Carl Djerassi (Stanford University), George S. Hammond (University of California), Russell A. Bonham (University of Indiana), John D. Baldeschwieler (Caltech), Robert E. Ireland (Caltech), William S. Johnson (Stanford) and Aron Kuppermann (Caltech). The Brazilian team was composed by Paschoal E. A. Senise, Ernesto Giesbrecht, Bruce Kover, Simão Mathias, Eduardo M. A. Peixoto, Eloisa Mano, Vicente G. Toscano, José Manuel Riveros, Walter B. Mors, Manuel da Frota Moreira, Peter Seidl, and Nicola Petragnani. The major goal was to promote international competitive research in Brazil, preventing the brain drain in the Brazilian Science marked by the increasing loss of bright students and scientists, attracted by the better opportunities and conditions offered by the developed countries. By promoting the internationalization of Science (Chemistry), the

*e-mail: henetoma@iq.usp.br program opened important new gates for international cooperation with the Brazilian Universities.

In the NAS/CNPq program, the major role was played by a fantastic team of young, brave American and English post-doctoral fellows who accepted the challenge of conducting internationally competitive research, under the rather primitive supporting conditions offered by the Brazilian Universities at that time, not mentioning the language and cultural differences. Many of them succeeded, and kept evolving in their career after returning to their countries. Some reached top positions in the Scientific World, such as Sir Simon F. Campbell (Viagra's discover, Royal Society of Chemistry President), Richard G. Weiss (Langmuir's Editor), and John M. Malin (ACS director of international cooperation). Some preferred to stay in Brazil, becoming highly ranked scientists such as Timothy J. Brocksom (UFSCar) and Frank H. Quina (USP). On the other hand, the first generation of Brazilian students team was composed by doctoral students such as Henrique E. Toma (USP), Antonio S. Mangrich (UFRJ, President of the Brazilian Chemical Society), Luiz Antonio Andrade de Oliveira (UNESP-Araraquara, Professor), Augusto Coelho (UFCE, Professor) and Mercedes Solano Pereira (USP), as well as by the several students directly supervised by the Brazilian top scientists participating in the Program.

The internationalization program involved a heavy calendar of activities, including visits, workshops and seminars, in addition to high level courses in Chemistry. The graduate program at the Institute of Chemistry was completely renewed, encompassing many parallel initiatives of internationalization in the area of Natural Products, including strong investments in Nuclear Magnetic Resonance facilities at the University. In the same period of time, the Department of Biochemistry received large support from the local Bioq/FAPESP initiative, and the Institute became a reference center in Chemistry, Natural Products and Biochemistry.

In Brazil, as a consequence of such successful programs, the graduate students were stimulated to move into the best Universities in USA and Europe, and were also well received by the Professors from the NAS/CNPq program, expanding their scientific heritage in Brazil. In particular, Taube's School was expanded with new Brazilian researchers, such as Douglas W. Franco (USP, São Carlos), Elia Tfouni (USP-Ribeirão Preto), and Fábio S. Nunes (UFPR), followed by other generation of students. Reflecting Henry Taube's direct influence, the ruthenium element became an important research theme in the Brazilian Chemistry repertoire.

The NAS/CNPq program also inspired important initiatives in Brazil, such as the PADCT Program (1985-2005) which extended the investments in research and facilities to all the universities in Brazil, thus shaping the current explosion of Chemistry all over the country. Nowadays, internationalization has been claimed as an important goal to be achieved in Brazilian Science, but only few really understand its connection with the NAS/CNPq program, and especially with Henry Taube.

Taube's legacy to Science started with the concepts associated with the labile and inert character of the metal ion complexes, 
followed by the electron transfer theory and then, by the intervalence transfer processes. The new vision of chemical reactivity in transition metal complexes renewed completely the area of Inorganic Chemistry, stimulating the interest on the reaction mechanisms, particularly in biological systems and catalysis. His special preference to ruthenium chemistry was associated with the so called back-bonding interaction, where the metal ion acts as an electron donor, departing from the classical Lewis acid behavior, in the presence of unsaturated or $\pi$-acceptor ligands. His mixed valence complexes dominated the interest of inorganic chemists for more than two decades, since 1970, pushing dramatic pressure on electronics and conducting material research. The consequences are now quite evident by the reborn of materials chemistry in the nanotechnology era. As a matter of fact, the outstanding conductivity of many mixed valence metal oxides, surpassing those of the pure metal elements, is one of the great advances in the current electronic devices. Electron transfer became a fundamental aspect of electronics, biochemistry, electrochemistry and catalysis, and its essence is strongly connected to Henry Taube's history. ${ }^{2}$

\section{REFERENCES}

1. Toma, H. E.; J. Braz. Chem. Soc. 2005, 16, editorial, doi:10.1590/S010350532005000700001.

2. Creutz, C.; Ford, P. C.; Meyer, T. J.; Inorg. Chem. 2006, 45, 7059. 